\title{
Análise dos comentários de notícias sobre violência contra as mulheres
}

Helena Salgueiro Lermen. Universidade do Estado do Rio de Janeiro Sabrina Daiana Cúnico. Pontifícia Universidade Católica do Rio Grande do Sul

\section{Resumo}

Diversos foram os avanços no campo legal no que diz respeito ao combate à violência de gênero. Porém, ainda é frequente a veiculação de reportagens na mídia que atestam a ocorrência de casos de agressão contra as mulheres. $O$ objetivo deste artigo foi analisar, por meio da análise crítica do discurso, os comentários de internautas publicados em resposta às reportagens que tratam sobre estes casos, veiculadas em dois portais nacionais de notícias. A partir desta análise, concluímos que as alterações nas legislações acerca da violência contra as mulheres não parecem estar sendo acompanhadas de mudanças de paradigmas de gênero. Isto porque, de modo geral, a culpabilização das vítimas foi seguida da minimização da agressão praticada pelos homens, revelando o quanto as mulheres ainda são vistas como objetos e propriedades masculinas. Situação que aponta para a necessidade do desenvolvimento de ações estatais que sejam sustentadas pela mudança das assimetrias de gênero.

Palavras-chave: violência; gênero; mídia.

\begin{abstract}
Analysis of news comments about violence against women. Several were advances in the legal field with regard to combating gender violence. However, media news attesting the occurrence of cases of aggression against women is still frequent. This paper aimed to analyze, through critical discourse analysis, netizens' comments posted in response to news that deal with these cases, broadcasted in two Brazilian news portals. From this analysis, we concluded that the changes in legislation on violence against women do not seem to be accompanied by changes in gender paradigms. In general, this is because victims' blaming was then followed by the minimization of the aggressions practiced by men, revealing how women are still seen as objects and men's properties. This situation points to the need to develop state actions that are sustained by changing gender asymmetries. Keywords: violence; gender; media.

\section{Resumen}

Análisis de los comentarios de noticias sobre la violencia contra las mujeres. Muchos fueron los avances en el ámbito legal respecto al combate a la violencia de género. Sin embargo, aún es frecuente la publicación de reportajes en los medios de comunicación que confirman la ocurrencia de casos de agresión contra las mujeres. El objetivo de este estudio fue analizar, a través del Análisis Crítico del Discurso, los comentarios de los internautas publicados en respuesta a los reportajes que tratan de estos casos, divulgados por dos portales nacionales de noticias. A partir de este análisis, se concluye que las alteraciones en la legislación sobre la violencia contra las mujeres no parecen estar acompañadas de cambios en los paradigmas de género. Esto se debe a que, en general, se culpa las víctimas y se minimiza la agresión practicada por los hombres, esto revela cuanto las mujeres aún son consideradas como objetos y propiedades masculinas. Esta situación apunta a la necesidad de desarrollar acciones estatales que sean sustentadas por el cambio de las asimetrías de género.
\end{abstract}

Palabras clave: violencia; género; medios de comunicación. 
De acordo com o Conselho Nacional de Justiça (2013), entre os anos de 1980 e 2010 houve um aumento de $230 \%$ do número de mulheres vítimas de assassinato no Brasil. O crescimento maior se deu na última década, entre os anos de 2000 e 2010, computando mais de 43 mil homicídios neste período. Dados mais atuais, divulgados pelo Mapa da Violência (Waiselfisz, 2015), indicam que somente no ano de 2013, mais de 4.700 mulheres foram assassinadas, uma estimativa de 13 homicídios femininos diários naquele ano. No que tange à violência sexual, o Instituto de Pesquisa Econômica Aplicada - IPEA- (2014), com base nos registros fornecidos pelo Ministério da Saúde, concluiu que $89 \%$ das vítimas deste tipo de violência são do sexo feminino e possuem baixa escolaridade. A pesquisa também identificou que $70 \%$ dos estupros são cometidos por namorados, parentes ou amigos/conhecidos das vítimas.

A violência contra a mulher não é um fenômeno recente no país. Em 1994, por exemplo, o Brasil assinou o documento da Convenção Interamericana para Prevenir, Punir e Erradicar a Violência contra a Mulher, também conhecida como Convenção de Belém do Pará. Tal convenção definiu a violência contra a mulher como "qualquer ato ou conduta baseada no gênero, que cause morte, dano ou sofrimento físico, sexual ou psicológico à mulher, tanto na esfera pública como na esfera privada" (Organização dos Estados Americanos, 1994, p. 01).

Uma legislação específica de combate à violência contra as mulheres, porém, só foi sancionada 12 anos depois, através da Lei 11.340 de 07 de agosto de 2006, mais conhecida como Lei Maria da Penha. Essa legislação surgiu após o Brasil ser condenado pela Comissão Interamericana de Direitos Humanos por conta de sua negligência em relação aos casos nacionais de violência doméstica e, em especial, pela omissão nos episódios de agressão e de tentativa de homicídio dos quais Maria da Penha Maia Fernandes foi vítima (Organização dos Estados Americanos, 2001). Uma das contribuições mais importantes da Lei 11.340/06 é de que a violência contra a mulher deixa de ser um crime de pequeno potencial ofensivo. Assim sendo, as penas dos condenados não podem mais ser pagas com cestas básicas ou multas.

A Lei Maria da Penha tipifica a violência doméstica e familiar contra mulher de cinco formas. A primeira é a violência física, que envolve agressão à integridade ou à saúde corporal. A segunda é a violência psicológica, que diz respeito às condutas que geram danos emocionais, diminuição da autoestima, prejuízo e perturbação do desenvolvimento ou degradação de comportamentos, crenças e decisões. A terceira é a violência sexual, a qual envolve ações que constranjam mulheres a presenciar, manter ou participar de relação sexual não consentida; atos que induzam à prostituição; e condutas que impeçam o uso de métodos contraceptivos, limitem ou anulem o exercício dos direitos sexuais e reprodutivos. A quarta forma de violência é a patrimonial, entendida como ações de retenção, subtração e destruição de objetos, instrumentos de trabalho, documentos pessoais, bens, dentre outros. Por fim, a quinta é a violência moral, que engloba qualquer ato de calúnia, difamação ou injúria. Já em 2015, nove anos após a entrada em vigor da Lei $n^{\circ} 11.340 / 06$, o IPEA divulgou um relatório em que avalia como positivo o impacto dessa lei. O documento informa que desde 2006, a taxa de homicídios de mulheres dentro de casa se manteve estável em 5,43 óbitos para cada 100 mil mulheres. 0 IPEA entende que esse número seria $10 \%$ maior se não houvesse a aplicação da lei (IPEA, 2015).

Embora tal estabilização seja um importante indicador, a taxa de assassinatos femininos no país ainda é alarmante. Como resposta, o Estado sancionou a Lei $\mathrm{n}^{\circ} 13.104$, de 9 de março de 2015, que alterou o Código Penal, prevendo o feminicídio como circunstância qualificadora do crime de homicídio. A lei também modifica o

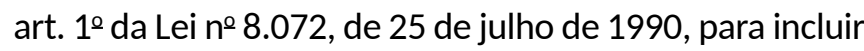
o feminicídio no rol dos crimes hediondos. Por feminicídio, a legislação entende que o crime foi praticado contra a mulher por razões da condição de sexo feminino, envolvendo tanto violência doméstica e familiar, quanto o menosprezo ou discriminação à condição de mulher.

Embora avanços no campo legal sejam constatados, a ocorrência de casos de agressão contra as mulheres é atestada na mídia com frequência. Notícias com esse teor são vinculadas nos meios de comunicação e são amplamente comentadas por internautas em sites e redes sociais. Em meio aos comentários de pessoas que se identificam com a vítima e demonstram seu desconforto com a situação vivenciada por ela, também são frequentes os comentários agressivos e que culpabilizam a mulher pela violência sofrida, seja essa letal ou não.

Diante do exposto, o objetivo do presente trabalho foi analisar os comentários de internautas publicados em resposta às reportagens de violência contra as mulheres. Por meio da Análise Crítica do Discurso (Van Dijk, 2008), a investigação se deu a partir de três categorias: violência sexual, violência física e violência 
psicológica. Vale mencionar que, em nossa análise, partimos de um referencial analítico de gênero, adotando uma perspectiva relacional da violência, a qual está na base da definição de gênero (Medrado \& Lyra, 2008).

\section{Questões de gênero}

Segundo Scott (1990), o conceito de gênero vai além dos determinantes biológicos que diferem homens e mulheres, tratando de construções sociais e relacionais. Para a autora, o termo gênero engloba tanto os domínios estruturais e ideológicos nas interações entre os sexos, como também exige uma posição analítica de questionamento dos paradigmas históricos que existem nessas relações.

Para Saffioti (1999), a concepção de gênero não deixa necessariamente explícita as desigualdades entre homens e mulheres, embora a primazia masculina seja facilmente presumida. Tais desigualdades não são naturais, mas constituídas no tecido social, através das estruturas de poder, das tradições culturais e das relações entre os atores envolvidos.

Essas desigualdades marcam também os estereótipos de gênero, ou seja, os papéis que socialmente são esperados para homens e para mulheres. A partir do século XX, em função das Grandes Guerras, as mulheres ampliaram seus papéis na sociedade através da inserção no mercado de trabalho. A saída da esfera privada (doméstica) para pública foi um avanço, porém gerou poucas mudanças nos estereótipos de gênero femininos. Ainda hoje são vinculadas aos homens as imagens e as expectativas de instrumentalidade, enquanto as mulheres são relacionadas à expressividade. Os estereótipos de gênero também permanecem os mesmos se considerarmos as características físicas. Tal permanência se deve, em parte, à mídia, que cultua a beleza e a juventude como atributos desejáveis aos homens e fundamentais para as mulheres. Já a inteligência e a persistência são tidas como imprescindíveis para os homens e esperadas para as mulheres (D'Amorim, 1997).

Assim, mulheres e homens possuem diferentes modos e possibilidades de inserção e trânsito no campo social. Contudo, o repertório social tanto de mulheres quanto de homens não é definido apenas pelas questões de gênero, mas também pelos componentes de raça e de classe (Scott, 1990). Deste modo, o processo de socialização não é vivenciado da maneira homogênea nem mesmo entre as mulheres, pois depende desses outros dois eixos estruturantes da sociedade (Saffioti, 1999).
A violência, por sua vez, faz vítimas de todas as cores e classes sociais. Entretanto, não apenas a experiência de viver uma agressão, como também o julgamento moral que é feito a respeito das vítimas difere entre mulheres brancas e negras, ricas e pobres. Em um estudo sobre a prevalência e o perfil de violência de gênero, constatou-se que as mulheres negras sofrem mais agressões psicológica e física se comparadas a mulheres brancas (Kronbauer \& Meneghel, 2005).

Soma-se a isso a representação social da mulher negra, muito presente na sociedade brasileira e na literatura nacional, como uma figura estereotipada, sexualizada e marginalizada (Pereira, 2011), colocada em uma posição de alguém que não detém direito sobre o seu corpo e que não poderia, portanto, ser uma vítima. Desta maneira, como aponta Saffioti (1987), é a mulher negra e pobre a mais vulnerável a sofrer os mais diferentes tipos de violência.

\section{Violência contra a mulher: algumas questões teóricas}

No Brasil, a literatura que discorre sobre a violência contra as mulheres teve sua origem no início dos anos 80 , constituindo-se em uma das principais temáticas de estudo do movimento feminista. Nesta época, buscava-se dar visibilidade à violência cometida contra as mulheres, enfatizando meios de combatê-la mediante intervenções sociais, psicológicas e jurídicas. Uma das conquistas mais relevantes desse período foi a criação da primeira delegacia da mulher no Brasil e no mundo. Inaugurada na cidade de São Paulo em 1985, tinha como objetivo investigar crimes em que a vítima fosse uma mulher. No âmbito acadêmico, as pesquisas realizadas nessa época tinham por foco identificar quais eram os delitos mais denunciados, além de conhecer quem eram os agressores e quais mulheres mais sofriam violência (C. M. Santos \& Izumino, 2005).

A partir dos anos 90, sob a influência dos debates norte-americanos e franceses e a ampliação das discussões do conceito de gênero nos estudos feministas no Brasil, uma nova terminologia passou a ser utilizada para discutir o fenômeno da violência contra as mulheres: a expressão violência de gênero (C. $M$. Santos \& Izumino, 2005). No cerne dessa mudança de nomenclatura está o entendimento de que a violência possui uma perspectiva relacional. Perspectiva esta que está na base da definição do conceito de gênero (Medrado \& Lyra, 2008). 
Neste panorama de análise, é importante que uma breve distinção entre os conceitos de violência de gênero, violência doméstica e violência intrafamiliar seja realizada, visto que tais conceitos são, com frequência, usados erroneamente como sinônimos. A violência intrafamiliar é aquela que envolve membros de uma mesma família, seja ela extensa ou nuclear. Este tipo de violência pode acontecer no interior do domicílio ou fora dele, embora o primeiro caso seja o mais comum. A violência doméstica apresenta pontos de sobreposição à familiar. A diferença é que ela atinge também pessoas que não pertençam à família, desde que vivam parcial ou integralmente no domicílio do agressor (Saffioti, 2004).

A violência de gênero, por sua vez, é entendida como uma categoria de violência mais geral, que pode abarcar a violência doméstica e a violência intrafamiliar. Ainda que a violência de gênero possa ser perpetrada por um homem contra outro homem ou por uma mulher contra outra mulher, o mais comum é a violência praticada por homens contra as mulheres (Saffioti, 2004). Nesse sentido, a violência doméstica e familiar contra a mulher é identificada como uma violência de gênero, com todas as suas implicações políticas, históricas e culturais, e não como uma violência de sexo, limitada ao corpo e/ou às experiências individuais de homens e mulheres (Medrado, Lemos, \& Brasilino, 2011).

Para Saffioti (1997; 1999; 2001), no entanto, é necessário que o debate a respeito da violência contra a mulher não se paute de forma reducionista no binômio dominação-vitimização. A autora critica a corrente vitimista que entende a mulher em situação de violência como não-sujeito, ou seja, sendo incapaz de reagir e de oferecer resistência nos casos de violência perpetrada pelos homens. Para ela, ainda que muitos homens dispensem às mulheres um tratamento de não-sujeitos e muitas delas se vejam efetivamente como tais, as relações sociais só se dão efetivamente entre indivíduos, não se admitindo a possibilidade que uma pessoa se converta em objeto, ainda que seja assim tratada.

Com base neste entendimento, a autora em pauta defende que, ainda que algumas reações não sejam suficientes para pôr fim à violência sofrida, as mulheres - se não em todos os casos, na maioria deles - sempre reagem contra o agressor, das mais diversas maneiras. Isto não significa dizer, contudo, que as mulheres em situação de violência não são vítimas ou que são cúmplices da violência sofrida. Mesmo porque, para que pudessem ser cúmplices e consentir com esta violência, precisariam desfrutar de poder semelhante ao dos homens, o que não ocorre. As mulheres são sim vítimas, mas isto não significa torná-las passivas (Saffioti 1997; 1999; 2001).

A mesma lógica que vai contra a ideia de vitimização das mulheres, busca não compactuar com o mecanismo de patologização dos homens agressores, por entender que assumir tal perspectiva é ignorar as hierarquias e contradições sociais (Saffioti, 1999; 2001). Em outras palavras, ao assumirmos a posição que considera a mulher sempre vítima e o homem sempre algoz, não abrimos espaço para que as relações de poder possam ser ressignificadas e reformuladas. Nesse sentido, as considerações aqui tecidas visam ilustrar a complexidade da temática da violência contra as mulheres, buscando ampliar a discussão para além de uma lógica reducionista e binária: homens violentos e mulheres passivas.

\section{Mídia e estereótipos de gênero}

É fato que a mídia, seja ela televisiva, digital ou impressa, possui um papel relevante tanto para a transformação da realidade social, quanto para a consolidação desta mesma realidade (Biroli, 2011; Miguel \& Biroli, 2009). O papel central que a mídia ocupa neste processo é possibilitado, em grande medida, pelo fato de que ela aparece aos olhos do público como sendo imparcial, ou seja, como tendo a função de apenas transmitir a informação sem influenciar a capacidade reflexiva das pessoas.

A binarização do mundo dos sexos em polos - praticamente opostos - do que seria próprio para homens e do que seria indicado para as mulheres nas esferas afetiva, profissional e/ou política, definem o que chamamos de estereótipos de gênero (Heredia, Ramos, Sarrió, \& Candela, 2002). Com base neste entendimento, podemos afirmar que "os estereótipos estão na base das representações da realidade que são internalizadas pelos indivíduos, orientando suas ações" (Biroli, 2011, p. 76).

Neste contexto, a mídia aparece como um instrumento importante para a propagação de aspectos da realidade social - que são apresentados como a própria realidade ou o que importa dela - que confirmam e naturalizam as desigualdades existentes entre homens e mulheres (Biroli, 2011; Miguel \& Biroli, 2009). A superação destas desigualdades fica prejudicada justamente pelo fato de que o controle das informações, ou seja, do que será transmitido e problematizado, está no centro da dinâmica de dominação (Biroli, 2011).

Em outros termos, entendemos que os meios de comunicação não só refletem as hierarquias de gênero, como também as promovem tendo um papel ativo na 
sua naturalização e manutenção (Miguel \& Biroli, 2009). É a partir deste entendimento que situamos a mídia não só como um espaço de veiculação, mas também de construção de discursos, produzindo significados e identidades (Fischer, 2001).

É possível perceber que a mídia utiliza modos muito específicos ao falar de diferentes grupos, tais como os jovens, os adolescentes, as crianças e as mulheres. Contudo, para cada um desses grupos existem outras diferenciações, como por exemplo, as mulheres jovens, adultas, idosas, as que são criminosas, prostitutas, modelos, as que pertencem à classe trabalhadora, as que pertencem ao cenário político e assim por diante (Fischer, 2001).

Assim sendo, para Miguel e Biroli (2009), o campo midiático reflete uma visão da mulher como "objeto de que se fala" (p. 65). Isto é, os discursos que são postos em circulação pela mídia reiteram perspectivas sobre a mulher que são influenciadas pelas diferenciações de gênero. Tais perspectivas se sobrepõem àquelas que poderiam trazer à tona as tensões, os confrontos e as dissonâncias que estão implicadas em relações assimétricas.

Neste contexto, os discursos sobre os cuidados com o corpo são recorrentes quando se fala de mulheres e para as mulheres na mídia. $O$ corpo feminino é retratado como "sua razão de ser, para si mesma e para o outro, para o desejo do outro" (Natansohn, 2005, p. 288). Paralelamente a esta lógica que estabelece o corpo da mulher como fonte de desejo, há a veiculação de discursos midiáticos que reforçam uma imagem do que seria apropriado ao gênero feminino, a qual incluiria elementos de recato, pudor e sobriedade. A respeito disto, Kehl (1998) afirma que as mulheres são herdeiras de discursos que, historicamente, definiram uma essência feminina eterna e universal, sendo ainda difícil para elas deixarem de ser objeto desta produção discursiva que estabelece uma suposta "verdade" sobre a sua natureza.

\section{Método}

Para a coleta de dados, buscamos reportagens em dois portais nacionais de notícias - Yahoo e Terra - que possuem amplo acesso, bem como permitem que os internautas possam fazer comentários em suas matérias. Determinamos o período de 09 de março de 2015 a 09 de julho de 2015 para realizar a coleta. Incluímos no nosso trabalho seis reportagens sobre quaisquer tipos de violência contra a mulher, que foram publicadas nos portais selecionados no período acima definido. Outro critério de inclusão foi que as notícias deveriam possuir pelo menos 10 comentários, de modo a analisar as interações entre os internautas. Salientamos que mantivemos a escrita original das postagens analisadas e não fizemos distinções a respeito do sexo da pessoa que emitiu a opinião em função de muitos perfis serem falsos ou anônimos.

A análise dos dados se deu através da Análise Crítica do Discurso (ACD), que objetiva reconhecer as relações entre discurso e poder nas relações e interações sociais. Este tipo de investigação discursiva concentra-se, em especial, nos problemas sociais, explicando-os por meio da estrutura e interação social. O discurso, portanto, é simultaneamente uma produção individual e social. A $A C D$ é sociopoliticamente situada, entendendo que o discurso se constituiu por elementos que se localizam tanto no macro quanto no micro nível (Van Dijk, 2008). Ao macro nível, procuramos entender de que modo os internautas se apropriam de discursos hegemônicos sobre os papéis e expectativas sociais que recaem sobre as mulheres. Já ao micro nível estão situadas as análises sobre a interação entre os internautas, as escolhas linguísticas e as estratégicas retóricas que se dão entre eles.

\section{Resultados e discussão}

Para fins de análise, optamos por separar as reportagens selecionadas de acordo com a tipologia de violência a que se referiam. Sendo assim, os resultados serão apresentados em três categorias, quais sejam: violência sexual, violência física e violência psicológica. Importante salientar que esta divisão atende a fins basicamente didáticos, uma vez que não desconsideramos que, na prática, atos violentos podem envolver mais de um tipo de violência.

\section{Violência Sexual}

As duas reportagens selecionadas para esta categoria foram divulgadas no portal de notícias do Yahoo e versam sobre a questão do abuso e da violência sexual, das quais as mulheres são as principais vítimas. Na primeira reportagem, uma repórter relata ter sido vítima de um homem que se masturbou e ejaculou em sua calça durante um trajeto no metrô de São Paulo. De acordo com a notícia, a repórter só percebeu que havia um homem se masturbando perto dela, quando este ejaculou em suas calças, situação que a fez tirar foto da calça manchada e denunciar o abuso para os responsáveis do metrô. Essa reportagem teve um total de 892 comentários. Neles, o descrédito dado à palavra da mulher adulta foi preponderante. "Conversa pra boi dormir, se acha que ela não iria sentir o cara batendo uma? Até empinou o c*" 
Estranho acho que essa mulher está falando mentira só pra ganhar indenização pois como assim alguém ejacula em vc e vc não sabe quem foi? nem pra onde essa pessoa foi? e na hora que ele estava executando o ato da ejaculação a reporte estava rindo? ou fazendo vista grossa? O que essa repórter estava fazendo? acho que é farsa! não estou defendendo o cara mas será que esse cara realmente existiu?

Salientamos que, nestes sites, é possível tanto fazer avalições favoráveis ou não ao que foi escrito, como responder o que foi comentado. Os comentários anteriores receberam, respectivamente, 10 avaliações positivas e duas negativas e 12 avaliações positivas e cinco negativas. Assim como estes usuários, vários outros se posicionaram com desconfiança no que tange a veracidade do fato contado pela repórter. Enquanto alguns defenderam que a história só poderia ser fantasiosa, outros afirmaram que a repórter certamente sentiu prazer e gostou da aproximação forçada do homem, uma vez que teria "permitido" que ele se masturbasse próximo a ela. Neste mesmo panorama, a culpabilização da repórter diante da violência sexual sofrida foi amplamente pontuada pelos internautas, como no comentário:

"A repórter também foi besta. Devia ter gritado e denunciado que a galera do vagão teriam descido a porrada no cara."

No caso da frase acima, foram 223 avaliações positivas e 63 negativas, indicando que a maioria das pessoas que leu o comentário parece concordar com o que o que foi escrito pelo internauta. Nas respostas a este comentário, algumas pessoas se manifestaram contrárias, reforçando que as vítimas não podem ser taxadas como culpadas. Já outras reforçaram o quanto o uso de roupas justas e a inação feminina tornam as mulheres responsáveis por situações como a vivenciada pela repórter.

A falta de confiança na palavra da mulher e a culpa atribuída às vítimas são apontadas pela literatura. Segundo Narvaz e Koller (2007), as mulheres que foram vítimas de violências sexuais têm os seus discursos de denúncia desacreditados, silenciados e culpabilizados. Já Cavalcanti, Gomes e Minayo (2006) descrevem a contradição entre as posições secundárias e subordinadas das mulheres frente aos desejos masculinos e a culpa atribuída a elas em casos de violência. Os comentários e repostas dos internautas são exemplos claros dos apontamentos desses autores.

No entanto, muito embora tais comentários ainda indiquem a perpetuação de uma lógica que posiciona a mulher vítima de violência sexual como sendo corresponsável pela violência sofrida, a legislação tem buscado endurecer as punições para os homens que cometem esses delitos. No ano de 2017, por exemplo, a Comissão de Constituição e Justiça (CCJ) do Senado aprovou duas propostas com o objetivo de punir casos de homens que ejaculam em passageiras em transportes coletivos. Um dos projetos propõe pena de reclusão de 2 a 4 anos para a pessoa que constranger, molestar ou importunar alguém de modo ofensivo ao pudor, mesmo que não haja contato físico. O outro projeto prevê a inclusão no Código Penal do crime de molestamento sexual, com pena de reclusão de 2 a 4 anos para quem constranger alguém mediante prática de ato libidinoso perpetuado sem violência ou grave ameaça, independentemente de contato físico ("Comissão aprova propostas", 2017). Importante salientar que essas propostas de leis sugiram após ampla divulgação midiática de casos de homens que ejacularam em passageiras de transportes coletivos.

A outra notícia analisada sobre violência sexual versa sobre o estrupo de uma menina de 12 anos, praticado por três adolescentes, dentro do banheiro de uma escola pública no Estado de São Paulo. Foram 790 comentários nessa reportagem, predominantemente voltados à questão da redução da maioridade penal em função da idade dos agressores.

E ainda acham que a pena para menor de idade não deve diminuir? E se fosse sua filha? Cada dia essas notícias me deixa mais convicta de que a lei tem que mudar. Pode estuprar, matar e roubar? Pode ser preso também!

O comentário acima teve 317 avaliações positivas e 13 negativas. Quase todas as 13 respostas à internauta apoiavam a Proposta de Emenda à Constituição - PEC 171/1993, que visa à alteração da redação do art. 228 da Constituição Federal, acerca da imputabilidade penal do maior de 16 anos. Outras réplicas ao comentário invocavam a justiça divina ou pregavam a lei do talião, desejando sofrimento físico e sexual aos agressores da menina. Contudo, uma das respostas destoava das demais, questionando "E se fosse o seu filho o estuprador?". Essa frase foi ocultada pelo Yahoo, por ter muitas avaliações negativas (17 no total). Ao que parece, para esses internautas, a punição de Deus e dos homens não deve ser aplicada a todos.

Notamos que as duas notícias sobre violência sexual geraram enorme repercussão. Juntas, elas tiveram mais de 1600 comentários. Mentz e Schmidt (2017) propõem que reportagens como a da mulher adulta são escritas contendo excesso de informações, o que pode, de algum modo, ser entendidas pelos internautas como justificativa para o ato abusivo. Tal abordagem midiática 
incentiva "o leitor a buscar algum culpado para o fato que não seja o próprio agressor, transferindo responsabilidades e culpabilizando outros indivíduos que não o criminoso" (Mentz \& Schmidt, 2017, p. 13). Contudo, o modo discursivo como as reportagens descrevem a violência sexual, fundamenta, em parte, as reações dos internautas. A culpabilização da vítima vai além disso, e diz respeito à nossa sociedade machista.

Ainda, o entendimento de quem é vítima ou não de violência sexual é bastante variável. Embora as duas reportagens tratem de temas semelhantes - da mulher vista e tomada como um ser violável - a posição assumida pelas pessoas nos comentários de ambas as reportagens foi diametralmente oposta. Enquanto a notícia da mulher adulta que narrou o abuso sofrido no metrô foi constantemente desacreditada, sendo ela mesma, de certa forma, culpabilizada pelo ato, a reportagem da adolescente estuprada recebeu inúmeros comentários de apoio à vítima e comentários concordando com a pena de morte e a castração dos envolvidos no estupro.

\section{Violência Física}

Para esse tópico selecionamos duas reportagens sobre agressões físicas sofridas por mulheres. A primeira notícia foi retirada no portal do Yahoo e trata da decisão de um juiz de submeter a júri popular um homem que foi flagrado por câmeras de segurança dando uma cotovelada em uma mulher na saída de uma festa. Essa reportagem teve 17 comentários, a maioria parabenizando o juiz por sua ação e desejando que o homem receba uma pena exemplar. Apenas um comentário tentava minimizar a culpa do agressor:

Eu acho que ele deveria responder por lesão corporal porque ninguém viu e nem sabe o que ela falou, bem baixinho, no ouvido dele, antes da cotovelada. Uma vez, numa discussão, uma mulher falou pra mim: "abaixa a voz pra mim, porque além de preto, você tem cara de que dá essa b.u.n.d.a. fedida e também preta." Tive que me controlar para não fazer o mesmo.

Esse comentário não teve nenhuma resposta, foi avaliado positivamente uma vez e negativamente por duas pessoas. É interessante que apenas esse internauta culpabiliza a vítima. Vimos no tópico anterior, sobre violência sexual, que a palavra da mulher é frequentemente desacreditada e podemos conjecturar que se não houvesse a filmagem, a veracidade da agressão sofrida pela mulher provavelmente seria questionada.

A segunda reportagem selecionada nesse tópico foi publicada no portal Terra e trata de um caso ocorrido na África do Sul, em que homem colou a vagina de sua companheira, por suspeitar que ela o estava traindo. $\mathrm{Na}$ notícia, a mulher relata o histórico de agressões domésticas e revela temer por sua vida, pois seu marido está foragido. A notícia teve 29 comentários e mais da metade deles fazia piada com o fato descrito.

"Se é no Brasil ia faltar cola com certeza. Kkkkkkk

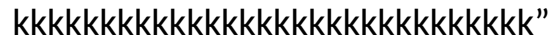

Esse comentário foi avaliado positivamente quatro vezes. Ninguém se manifestou contrário, nem houve respostas ao que esse internauta escreveu. A falta de crítica quanto ao ato do agressor pode se dar em função de a violência ter ocorrido entre cônjuges. O famoso ditado popular "em briga de marido e mulher, ninguém mete a colher" evidencia o quanto a violência doméstica é socialmente naturalizada. Deste modo, a dominação masculina é legitimada (Diniz, Almeida, Lopes, Gesteira, \& Oliveira, 1999) o que costuma dificultar o rompimento do ciclo de violência em que as mulheres estão envolvidas. Além disso, a suposta infidelidade feminina justificaria a agressão sofrida, visto que apenas os homens têm autorização social para a poligamia. Nesse sentido, a atitude agressiva do homem serve para recuperar seus status, honra e poder perante a mulher. As relações extraconjugais femininas são, inclusive uma das principais razões apontadas por homens para violentar suas parceiras (Oliveira \& Gomes, 2011).

Ainda sobre o comentário acima, destacamos que estudos feministas têm demonstrado o quanto a violência de homens contra suas companheiras ocupa também uma dimensão sociocultural, através de músicas, ditados populares e piadas. Assim, a agressão perpetrada por homens ganha um caráter pejorativo e socialmente aceitável, fomentando as desigualdades de gênero (M. I. D. Santos, 2004). O tom jocoso nos comentários reafirma o machismo de nossa sociedade, em que os corpos femininos são propriedades masculinas, demonstrando a representação social das mulheres como seres inferiores e subordinados aos homens.

Houve ainda comentários pontuando que somente a vagina da mulher havia sido colada, logo, outros orifícios da vítima poderiam servir para penetração peniana. Tais colocações dos internautas reforçam a ideia de que os corpos femininos são propriedades dos homens, sobretudo quando esses são seus parceiros sexuais.

Nesse tópico vimos dois exemplos distintos de violência física. No primeiro, o flagrante de agressão ocorrido em esfera pública, fez com que quase todos os internautas se posicionassem a favor da punição do homem, ainda mais porque não havia qualquer envolvimento 
entre agressor e vítima. Em contrapartida, o segundo trata de um caso sucedido em âmbito doméstico envolvendo violência entre cônjuges. Os comentários para essa última notícia são majoritariamente jocosos, culpabilizando a mulher ou ignorando a agressão sofrida por ela. As diferentes reações dos internautas expõem o quanto a violência conjugal é naturalizada e banalizada.

\section{Violência Psicológica}

Ambas as reportagens selecionadas para este tópico foram retiradas do portal de notícias Terra. A primeira delas contava a história de três estudantes que foram perseguidas nas redes sociais por meio de insultos, ameaças e ofensas. Entre os perseguidores, dois eram ex-companheiros das vítimas que não aceitavam o término do relacionamento e um era um "amigo virtual", que criou mais de 10 perfis falsos para tentar manter a todo custo o contato com uma das estudantes.

Esta reportagem teve 26 comentários, sendo a maioria deles emitidos em interação entre os internautas. De um lado havia quem culpabilizava e responsabilizava as mulheres pelas perseguições e agressões sofridas, argumentando que estas atitudes seriam resultado das posturas não condizentes com as atitudes de uma "mulher decente". O comentário abaixo é ilustrativo nesse sentido:

Você ve pelos relatos que os jovens não namoram mais, é sexo de cara, tipo animal no cio, uma refere que só foi dormir na casa do cara uma vez (dormir mudou o sentido) e dai chegaram trocando as pernas provavelmente bêbados e drogados e dai o cara ESTUPROU ela. Quem tem vida de pessoa da "vida" esta sujeita a crimes e a tudo realmente. Nem tem 18 anos e já deu pra todos que quiserem, não são mulheres decentes realmente, todas agem como prostitutas e os homens sabem o que são mulheres deste tipo e NUNCA vão respeitar elas. Pode passar mais mil anos mas macho sempre vai ser macho e mulher sem compostura sempre vai ser vítima.

A opinião desse internauta teve apenas uma avaliação positiva, mas suscitou diversas réplicas, tanto de aprovação quanto de reprovação. Em resposta a um comentário que dizia que o mundo não precisava de pessoas com pensamentos semelhantes ao retratado no comentário anterior, o mesmo internauta respondeu:

É gente com o seu pensamento que enche páginas policiais por serem "desaparecidas", peladas em marcha pra fazer aborto, em tribunal querendo pensão por filho que usam $\mathrm{p} /$ não fazerem nada e enchendo de menor infrator e miseravel em todos os sentidos, minha cara! Mulher sem vergonha na cara já era como sempre já foi!

Diante do exposto, é possível identificarmos que a crítica feita pelo internauta no que tange os comportamentos das mulheres - os quais ele julga inadequados - não é acompanhada da mesma forma por uma crítica a respeito dos comportamentos agressivos e ameaçadores dos homens. Situação que reflete a discrepância entre o que é esperado e aceito socialmente como comportamentos femininos e masculinos. Ao passo que delas se exige que sejam submissas e recatadas, eles são autorizados a se portar de modo agressivo como forma de "provar" a sua masculinidade (Torrão Filho, 2005). A respeito disto, Gomes (2008) pontua que, de fato, as articulações entre masculinidade e violência estão cada vez mais acentuadas, o que faz com que atos violentos perpetrados por homens sejam vistos como resultantes da própria condição de homem: um pleonasmo do exercício da masculinidade.

A segunda reportagem selecionada para este tópico trata de medidas que diversos países adotaram ou estão adotando para criminalizar as 'cantadas' em locais públicos, sinalizando quais as punições previstas para os agressores. O objetivo das medidas apresentadas na notícia é minimizar e acabar com a intimidação nas ruas, seja ela verbal ou por meio de contato físico com conotação pejorativa. Esta notícia teve 30 comentários, sendo em sua maioria opiniões que criticavam a criminalização deste tipo de assédio.

"...aliás...é uma incoerência danada...as mulheres querem ter o direito der andar peladas para chamar atenção, mas não querem chamar a atenção...meio esquisito isso...".

O comentário anterior teve quatro avaliações positivas e nenhuma negativa. De acordo com esse internauta, as mulheres que reivindicam seu direito de andar nas ruas da forma como se sentirem melhor não o fazem por si, por um bem-estar seu, mas sim com o objetivo de chamar a atenção dos homens. Assim, as mulheres que desaprovam as "investidas" masculinas seriam aquelas que se incomodam por não as receberem. Da mesma forma que esse internauta, diversos outros emitiram opiniões que apontavam para uma visão da mulher como um ser sexualmente disponível e ansiosa por ser desejada pelos homens. Assim, para os sujeitos que emitiram esses comentários, há uma ideia de feminilidade como sinônimo de atração sexual e, desta forma, disponibilidade para os homens (Gubernikoff, 2009). 
Salientamos que a violência psicológica é apontada pela literatura como a mais frequente e a menos enfatizada na sociedade (Gadoni-Costa, Zucatti, \& Dell'Aglio, 2011). Isso ocorre, sobretudo, pela ausência de marcas visíveis nos corpos femininos. Não surpreende, portanto, que a maioria dos comentários não reconheça a violência decorrente de perseguições e ameaças nas redes sociais, ou de "cantadas" na rua. Na realidade, no primeiro caso as mulheres foram culpabilizadas pelas ameaças e agressões sofridas. No segundo, a situação desagradável e o incômodo gerados nas mulheres em função das investidas recebidas por homens nas ruas não foram nem sequer considerados como agressão.

\section{Considerações finais}

No presente estudo buscamos analisar os comentários publicados por internautas a respeito de reportagens sobre violência contra as mulheres. Os conteúdos dos comentários atestaram a descrença e a desconfiança no relato das mulheres que sofreram alguma forma violência. A culpabilização das vítimas foi acompanhada da minimização ou negação da agressão praticada por homens, revelando o quanto as mulheres ainda são vistas como objetos e propriedades masculinas. Ainda, a maior parte dos comentários emitidos demonstrou o quanto a violência perpetrada por homens é socialmente autorizada e validada. A punição penal ou a retaliação aos agressores foi exaltada pelos internautas somente quando a violência foi praticada por menores de idade ou quando foi flagrada por câmeras.

Assim, vemos a defesa de discursos hegemônicos no que se refere às atribuições socialmente esperadas para homens e mulheres. As alterações nas legislações acerca da violência contra as mulheres não parecem estar sendo acompanhadas de mudanças de paradigmas de gênero. Cabe aqui uma reflexão acerca da lei do feminicídio. Se por um lado ela é vista como uma conquista histórica, pois está pautada na violência de gênero (tipificação de violência que não estava especificada na Lei Maria da Penha), por outro lado não vemos ações estatais de educação voltadas aos homens. O Estado opta, por exemplo, por criar vagões específicos para mulheres em metrôs, mas não investe em campanhas educativas sobre o respeito às mulheres nesses locais. As assimetrias de gênero precisam estar em pauta em diversos espaços, se quisermos mudar a cultura machista. Não desconsideramos a importância de medidas legais e penais, mas precisamos pensar se superlotar ainda mais o sistema prisional é o único meio de lidar com a violência contra as mulheres.

\section{Referências}

Biroli, F. (2011). Mídia, tipificação e exercícios de poder: a reprodução dos estereótipos no discurso jornalístico. Revista Brasileira de Ciência Política, (6), 71-98. doi: 10.1590/ S0103-33522011000200004

Cavalcanti, L. F., Gomes, R., \& Minayo, M. C. S. (2006). Representações sociais de profissionais de saúde sobre violência sexual contra a mulher: estudo em três maternidades públicas municipais do Rio de Janeiro, Brasil. Cadernos de Saúde Pública, 22(1), 31-39. doi: 10.1590/S0102-311X2006000100004

Comissão aprova propostas sobre assédio sexual em transporte público (2017, 27 de setembro). Recuperado de https://www12. senado.leg.br/noticias/materias/2017/09/27/comissao-aprova-propostas-sobre-assedio-sexual-em-transporte-publico

Conselho Nacional de Justiça (2013). Poder judiciário na aplicação da Lei Maria da Penha. Brasília. Recuperado de http://www.cnj.jus.br/ images/programas/lei-maria-da-penha/cartilha_maria_da_penha.pdf

D’Amorim, M. A. (1997). Estereótipos de gênero e atitudes acerca da sexualidade em estudos sobre jovens brasileiros. Temas em Psicologia, 5(3), 121-134. Recuperado de http://pepsic.bvsalud.org/scielo.php?script=sci_arttext\&pi$d=S 1413-389 X 1997000300010 \&$ Ing=pt\&tIng=pt

Diniz, N. M. F., Almeida, M. S., Lopes, R. L. M., Gesteira, S. M. A., \& Oliveira, J. F. (1999). Mulher, saúde e violência: o espaço público e o privado. O Mundo da Saúde, 23(2), 106-112.

Fischer, R. M. B. (2001). Mídia e educação da mulher: uma discussão teórica sobre modos de enunciar o feminino na TV. Estudos Feministas, 9(2), 586-599. doi: 10.1590/ S0104-026X2001000200015

Gadoni-Costa, L. M., Zucatti, A. P. N., \& Dell'aglio, D. D. (2011). Violência contra a mulher: levantamento dos casos atendidos no setor de psicologia de uma delegacia para a mulher. Estudos de Psicologia, 28(2), 219-227. doi: 10.1590/S0103-166X2011000200009

Gomes, R. (2008). A dimensão simbólica da violência de gênero: uma discussão introdutória. Athenea Digital, (14), 237-243. Recuperado de https://dialnet.unirioja.es/servlet/articulo?codigo=2736191

Gubernikoff, G. (2009). A imagem: representação da mulher no cinema. Conexão - Comunicação e Cultura, 8(15), 65-77. Recuperado de http://www.ucs.br/etc/revistas/index.php/conexao/article/view/113/104

Heredia, E. B., Ramos, A., Sarrió, M., \& Candela, C. (2002). Más allá del "techo de cristal": diversidad de gênero. Revista Del Ministério de Trabajo e Assuntos Sociales, (40), 55-67. Recuperado de https:// dialnet.unirioja.es/servlet/articulo?codigo $=296669$

Instituto de Pesquisa Econômica Aplicada (2014). Estupro no Brasil, uma radiografia segundo os dados da Saúde. Recuperado de http://www.ipea.gov.br/portal/images/stories/PDFs/nota_tecnica/140327_notatecnicadiest11.pdf

Instituto de Pesquisa Econômica Aplicada (2015). Pesquisa avalia a efetividade da Lei Maria da Penha. Recuperado de http://www.ipea.gov. $\mathrm{br} /$ portal/index.php?option=com_content\&view=article\&id=24610

Kehl, M. R. (1998). Deslocamentos do feminino. Rio de Janeiro: Imago.

Kronbauer, J. F. D., \& Meneghel, S. N. (2005). Perfil da violência de gênero perpetrada por companheiro. Revista de Saúde Pública, 39(5), 695-701. doi: 10.1590/S0034-89102005000500001

Lei n. 11.340, de 7 de agosto de 2006 (2006, 7 de agosto). Cria mecanismos para coibir a violência doméstica e familiar contra a mulher, nos termos do § 80 do art. 226 da Constituição Federal, da Convenção 
sobre a Eliminação de Todas as Formas de Discriminação contra as Mulheres e da Convenção Interamericana para Prevenir, Punir e Erradicar a Violência contra a Mulher; dispõe sobre a criação dos Juizados de Violência Doméstica e Familiar contra a Mulher; altera o Código de Processo Penal, o Código Penal e a Lei de Execução Penal; e dá outras providências. Diário Oficial da União, seção 1.

Lei n. 13.104, de 9 de março de 2015 (2015, 9 de março). Altera o art. 121 do Decreto-Lei no 2.848 , de 7 de dezembro de 1940 - Código Penal, para prever o feminicídio como circunstância qualificadora do crime de homicídio, e o art. $1^{\circ}$ da Lei no 8.072 , de 25 de julho de 1990, para incluir o feminicídio no rol dos crimes hediondos. Diário Oficial da União, seção 1.

Medrado, B., Lemos, A. R., \& Brasilino, J. (2011). Violência de gênero: paradoxos na atenção a homens. Psicologia em Estudo, 16(3), 471478. doi: 10.1590/S1413-73722011000300014

Medrado, B., \& Lyra, J. (2008). Por uma matriz feminista de gênero para os estudos sobre homens e masculinidades. Estudos Feministas, 16(3), 809-840. doi: 10.1590/S0104-026X2008000300005

Mentz, M., \& Schmidt, S. P. (2017, setembro). Educação, comunicação e cultura: a culpabilização das vítimas infantis de violência sexual no jornalismo online brasileiro. Comunicação apresentada no $40^{\circ}$ Congresso Brasileiro de Ciências da Comunicação, Curitiba. Resumo recuperado de http://portalintercom.org.br/anais/nacional2017/resumos/R12-0551-1.pdf

Miguel, L. F., \& Biroli, F. (2009). Mídia e representação política feminina: hipóteses de pesquisa. Opinião Pública, 15(1), 55-81. doi: 10.1590/ S0104-62762009000100003

Narvaz, M., \& Koller, S. H. (2007). O feminino, o incesto e a sedução: problematizando os discursos de culpabilização das mulheres e das meninas diante da violação sexual. Revista Ártemis, 6, 77-84. Recuperado de http://www.periodicos.ufpb.br/ojs/index.php/ artemis/article/view/2127

Natansohn, G. L. (2005). O corpo feminino como objeto médico e "mediático" médico e "mediático". Estudos Feministas, 13(2), 287304. doi: 10.1590/S0104-026X2005000200004

Oliveira, K. L. C., \& Gomes, R. (2011). Homens e violência conjugal: uma análise de estudos brasileiros. Ciência \& Saúde Coletiva, 16(5), 2401-2413. doi: 10.1590/S1413-81232011000500009

Proposta de Emenda à Constituição. PEC 171/1993 (1993). Altera a redação do art. 228 da Constituição Federal (imputabilidade penal do maior de dezesseis anos). Recuperado de http://www.camara. gov.br/proposicoesWeb/fichadetramitacao?idProposicao=14493
Organização dos Estados Americanos (1994). Convenção Interamericana para prevenir, punir e erradicar a violência contra a mulher, "Convenção de Belém do Pará". Belém,PA. Recuperado de http://www.cidh.org/Basicos/Portugues/m.Belem.do.Para.htm

Organização dos Estados Americanos (2001). Comissão Interamericana de Direitos Humanos. Relatório $n^{\circ} 54 / 01$, caso 12.051 - Maria da Penha Maia Fernandes. Recuperado de https:// www.cidh.oas.org/annualrep/2000port/12051.htm

Pereira, M. R. A. (2011). Gênero e etnicidade na literatura de autoria feminina. In III Colóquio/l Encontro Nacional Mulheres em Letras. Belo Horizonte, Minas Gerais.

Saffioti, H. I. B. (1987). O poder do macho. São Paulo: Moderna.

Saffioti, H. I. B. (1997). Violência de gênero: o lugar da práxis na construção da subjetividade. Lutas Sociais, (2), 59-79. Recuperado de https://revistas.pucsp.br/index.php/ls/article/view/18789

Saffioti, H. I. B. (1999). Já se mete a colher em briga de marido e mulher. São Paulo em Perspectiva, 13(4), 82-91. doi: 10.1590/ S0102-88391999000400009

Saffioti, H. I. B. (2001). Contribuições feministas para o estudo da violência de gênero. Cadernos Pagu, (16), 115-136. doi: 10.1590/ S0104-83332001000100007

Saffioti, H. I. B. (2004). Gênero, patriarcado, violência. São Paulo: Fundação Perseu Abramo.

Santos, C. M., \& Izumino, W. P. (2005). Violência contra as mulheres e violência de gênero: notas sobre estudos feministas no Brasil. Estudios Interdisciplinarios de América Latina y El Caribe, 16(1), 147-164. Recuperado de http://eial.tau.ac.il/index.php/eial/article/view/482

Santos, M. I. D. (2004). Gênero e comunicação: o masculino e o feminino em programas populares de rádio. São Paulo: Annablume.

Scott, J. (1990). Gênero: uma categoria útil de análise histórica. Educação e Realidade, 15 (2), 5-22. Recuperado de http://www.seer. ufrgs.br/index.php/educacaoerealidade/issue/view/3059/showToc

Torrão Filho, A. (2005). Uma questão de gênero: onde o masculino e o feminino se cruzam. Cadernos Pagu (24), 127-152. doi: 10.1590/ S0104-83332005000100007

Van Dijk, T. A. (2008). Discurso e poder. São Paulo: Contextos.

Waiselfisz, J. J. (2015). Mapa da violência 2015. Homicídio de mulheres no Brasil. Recuperado de http://www.mapadaviolencia.org.br/ pdf2015/MapaViolencia_2015_mulheres.pdf

Helena Salgueiro Lermen, Mestre em Psicologia pela Pontifícia Universidade Católica do Rio Grande do Sul (PUC/RS), é doutoranda em Saúde Coletiva no Instituto de Medicina Social Universidade do Estado do Rio de Janeiro (IMS/UERJ). Endereço para correspondência: Rua Lúcio de Mendonça, 63, bloco 2/apto 704. Bairro Maracanã. CEP 20270-040. Rio de Janeiro, RJ, Brasil. Telefone: (21) 97311 0184. E-mail: hslermen@gmail.com

Sabrina Daiana Cúnico, Doutora em Psicologia pela Pontifícia Universidade Católica do Rio Grande do Sul (PUC/RS), é Professora no curso de Psicologia da Pontifícia Universidade Católica do Rio Grande do Sul (PUC/RS). E-mail: sabrinacunico@yahoo.com.br 
